\title{
Prevalence and Predictive Factors of Malignant Potential in Resected Gastric Subepithelial Tumors
}

\author{
Seung Kak Shin, Jun-Won Chung, Jung Hyun Lee, Yoon Jae Kim, Kwang Ahn Kwon, Dong Kyun Park, Woon Kee Lee ${ }^{1}$ \\ Departments of Internal Medicine and Surgery ${ }^{1}$, Gachon University Gil Medical Center, Incheon, Korea
}

Background/Aims: EUS is a useful method to differentiate malignant from benign gastric subepithelial tumors (SETs) and to determine resection. However, this results in unnecessary resections of benign gastric SETs. The aim of our study is 1 . to investigate clinical factors that may predict malignancy in gastric SET and 2. to determine how many of them have malignant potential in resected gastric SETs.

Materials and Methods: We retrospectively identified 111 patients who underwent pathologic confirmation for gastric SETs by surgical (104/111, 93.6\%) and endoscopic resection between February 2003 and April 2012 and analyzed the clinical, EUS findings and final pathologic diagnosis for these patients.

Results: The diagnostic accuracy of EUS for SETs was 58.6\% (51/87) and the rate of resection for benign SETs was 31.5\% (35/111). In multivariate analysis, old age ( $\geq 65$ ), as well as tumor size $(\geq 2 \mathrm{~cm})$ and location (upper or middle) were significant predictive factors for malignant potential of gastric SETs.

Conclusions: One-third of endoscopic and surgical resections are performed for benign SETs. Patient's age, tumor size, and location should be considered before resection of gastric SETs. In addition, more accurate tools for histologic confirmation should be developed in order to avoid unnecessary resection. (Korean J Helicobacter Up Gastrointest Res 2013;13:104-108)

Key Words: Subepithelial tumor; Predictive factor; Stomach; Endosonography

\section{INTRODUCTION}

A submucosal tumor (SMT) is located from deep mucosa to deeper serosa, therefore, subepithelial lesion is a more accurate term. ${ }^{1-4}$ Most gastric subepithelial tumors (SETs) are not associated with symptoms and are discovered incidentally during endoscopic or radiologic examination. Subepithelial lesions include a diverse array of benign, potentially malignant, and malignant lesions. EUS is the best imaging procedure for characterization of these lesions. ${ }^{5,6}$ EUS shows typical findings for lipoma, duplication cyst, and pancreatic nest, ${ }^{7-11}$ however in hypoechoic lesions, such as leiomyomas, gastrointestinal stromal tumors (GISTs) and schwannomas, EUS findings are insufficient for definite diagnosis. Determination of the histologic layer and the echotexture of the lesion can significantly narrow the differential diagnosis and may be di- agnostic in some cases.

Recently, all GISTs have been regarded as having some degree of malignant potential, ${ }^{12,13}$ and even small GISTs may present with malignant features on histologic examination or biologic behavior.

Several studies have attempted to compare the EUS features of benign tumors with those of malignant tumors in SET of the upper gastrointestinal (GI) tract. However, in these studies, not all GISTs were considered malignant potential or most studies were analyzed prior to introduction of the concept of GISTs. In addition, there are only few data on the percentage of malignancy in resected SETs.

Therefore, we conducted this study 1 . to evaluate the clinical and EUS features distinguishing benign from potentially malignant gastric SETs in a single center population and 2. to investigate the percentage of malignancy in resected gastric SETs.

\footnotetext{
Received: March 22, 2013 Accepted: May 15, 2013

Corresponding author: Jun-Won Chung

Department of Internal Medicine, Gachon University Gil Medical Center, 21, Namdong-daero 774beon-gil, Namdong-gu, Incheon 405-760, Korea

Tel: +82-32-460-3778, Fax: +82-32-460-3408, E-mail: junwonchung@hanmail.net, drgreen@gilhospital.com
}

Copyright $\odot 2013$ Korean College of Helicobacter and Upper Gastrointestinal Research

(a) The Korean Journal of Helicobacter and Upper Gastrointestinal Research is an Open-Access Journal. All articles are distributed under the terms of the Creative Commons Attribution Non-Commercial License (http://creativecommons.org/licenses/by-nc/3.0) which permits unrestricted non-commercial use, distribution, and reproduction in any medium, provided the original work is properly cited. 


\section{MATERIALS AND METHODS}

\section{Patients}

We retrospectively identified 111 patients who underwent pathologic confirmation for gastric SETs by surgical (104/111, 93.6\%) and endoscopic resection (7/111, 6.4\%) at Gachon University Gil Medical Center between February 2003 and April 2012 and analyzed the clinical, EUS findings and final pathologic diagnosis for these patients. Details of this study were approved by the Institutional Review Border (IRB) of Gachon University Gil Medical Center (IRB No. GIRBA2811-2012).

\section{Methods}

The gastric SETs were divided into two groups according to the pathologic diagnosis; benign $(n=35)$ and malignant potential ( $\mathrm{n}=76)$. Malignant potential defined as having widespread metastatic potential including all GISTs. Association between the various clinicopathological parameters including gender, age, tumor size, location, change of tumor size, originating layer and echogenicity in EUS, pattern of tumor growth, patient's symptoms, and the presence of malignant potential in histologic type of SETs was examined.

EUS examinations were performed using a radial scanning ultrasound endoscope (EU-M2000; Olympus, Tokyo, Japan) using scanning frequencies of 7.5 and $12 \mathrm{MHz}$. All examinations were performed under intravenous sedation (midazolam with or without propofol). The endoscopic and EUS charts, EUS photographs were reviewed by one of the authors (JW Chung), who was blinded to the final diagnosis. The following EUS features were recorded for all tumors: (a) maximal diameter, (b) presence of mucosal ulceration on endoscopy and/or EUS, (c) echogenicity in comparison with the surrounding normal proper muscle layer (hyperechoic or isoechoic), (d) homogenicity (homogenous or heterogenous), (e) presence of cystic spaces, hyperechogenic spots, and calcification, and (f) a pattern of tumor growth (inside or outside the gastric wall).

\section{Statistical analysis}

The Student t-test was used for assessment of patient's age and tumor size. Differences in gender, old age $(\geq 65)$, tumor size $(\geq 2 \mathrm{~cm})$, existence of patient's symptoms, and EUS findings between benign and malignant potential in gastric SETs were assessed using the $\chi^{2}$ test. Univariate analyses using the $\chi^{2}$ test were performed for identification of clinical and EUS features associated with malignant potential of gastric SETs. Variables with $P$ value $<0.05$ in univariate analyses were included in a forward stepwise multiple logistic regression model for identification of the independent predictors of malignant potential of gastric SETs. The $P$ value $<0.05$ was considered statistically significant. The odds ratios and their 95\% confidence intervals were used to predict malignant potential of gastric SETs. Statistical calculations were performed using SPSS ver. 18.0 for Windows Software (SPSS Inc., Chicago, IL, USA).

\section{RESULTS}

Of the 111 patients who underwent pathologic confirmation for gastric SETs by surgical (104/111, 93.6\%) and endoscopic resection, 76 (68.5\%) had a malignant potential.

Most of malignant potential was GIST (69/76, 90.8\%). Others with malignant potential included glomus (3/76, $3.9 \%)$, spindle cell sarcoma $(1 / 76,1.3 \%)$, mantle cell lymphoma $(1 / 76,1.3 \%)$, neuroendocrine tumor $(1 / 76,1.3 \%)$, and plasmacytoma $(1 / 76,1.3 \%)$. The rate of resection for benign SETs (leiomyoma, schwannoma, etc.) was 31.5\% (35/111). During the study periods, EUS was performed in $78.4 \%$ (87/111) of patients. The diagnostic accuracy of EUS for SETs was 58.6\% (51/87); most originated from the

Table 1. Comparison of Clinical Features in Benign or Malignant Gastric Subepithelial Tumors (Univariate Analysis)

\begin{tabular}{lccc}
\hline \multicolumn{1}{c}{ Variable } & $\begin{array}{c}\text { Benign } \\
(\mathrm{n}=35)\end{array}$ & $\begin{array}{c}\text { Malignant potential } \\
(\mathrm{n}=76)\end{array}$ & $P$ value \\
\hline Gender & & & 0.171 \\
$\quad$ Male & $16(45.7)$ & $26(65.8)$ & \\
Female & $19(54.3)$ & $50(34.2)$ & \\
Age (year) & $50 \pm 12$ & $61 \pm 12$ & 0.000 \\
$\quad<65$ & $30(85.7)$ & $44(57.9)$ & \\
$\geq 65$ & $5(14.3)$ & $32(42.1)$ & \\
Patient's symptoms & & & 0.542 \\
Absent & $19(54.3)$ & $42(55.3)$ & \\
Present & $16(45.7)$ & $34(44.6)$ & \\
\hline
\end{tabular}

Values are presented as $\mathrm{n}(\%)$ or mean $\pm \mathrm{SD}$. 
Table 2. Comparison of Endoscopic Ultrasonography Features in Benign or Malignant Gastric Subepithelial Tumors (Univariate Analysis)

\begin{tabular}{lccc}
\hline \multicolumn{1}{c}{ Variable } & $\begin{array}{c}\text { Benign } \\
(\mathrm{n}=28)\end{array}$ & $\begin{array}{c}\text { Malignant potential } \\
(\mathrm{n}=59)\end{array}$ & $P$ value \\
\hline Tumor size $(\mathrm{cm})$ & $2.7 \pm 1.3$ & $3.5 \pm 1.5$ & 0.017 \\
$<2$ & $8(30.8)$ & $3(5.7)$ & 0.005 \\
$\geq 2$ & $18(69.2)$ & $50(94.3)$ & \\
Tumor location & & & 0.000 \\
Lower & $13(48.1)$ & $7(11.9)$ & \\
Middle & $7(25.9)$ & $30(50.8)$ & \\
Upper & $7(25.9)$ & $30(37.3)$ & \\
Originating layer & & & 0.002 \\
Second layer (MM) & $6(22.2)$ & $7(12.3)$ & \\
Third layer (SM) & $7(25.9)$ & $2(3.5)$ & \\
Fourth layer (PM) & $14(51.9)$ & $48(84.2)$ & \\
Echogenicity & & & \\
Hypo & $15(62.5)$ & $35(68.6)$ & \\
Mixed & $7(29.2)$ & $14(27.5)$ & \\
Hyper & $2(8.3)$ & $2(3.9)$ & \\
Increased size & & & \\
Yes & $4(14.3)$ & $6(10.2)$ & \\
$\quad$ No & $24(85.7)$ & $53(89.8)$ & \\
Pattern of tumor growth & & & \\
Inside & $28(100)$ & $57(96.6)$ & 0.407 \\
Outside & $0(0)$ & $2(2.9)$ & \\
\hline
\end{tabular}

Values are presented as $\mathrm{n}(\%)$ or mean $\pm \mathrm{SD}$.

$\mathrm{MM}$, muscularis mucosa; $\mathrm{SM}$, submucosa; $\mathrm{PM}$, muscularis propria.

fourth layer $(63 / 87,72.4 \%)$. Clinical features in gastric SETs are shown in Table 1. And endosonographic features in gastric SETs are shown in Table 2.

The mean age of patients and the mean tumor size differed significantly between benign and malignant potential. Middle or upper tumor location showed greater malignant potential than lower.

The third layer appeared more frequently in benign gastric SETs and the fourth layer in malignant potential. However, there were 14 benign SETs in the fourth layer (seven schwannomas, five leiomyomas, one ectopic pancreas, and one hamartomatous inverted polyp).

The patient's gender, symptoms, echogenicity in EUS, change of size, and extramural lesion did not differ between benign and malignant potential of gastric SETs.

In multivariable analysis, old age (OR, 20.4; 95\% CI, 2.3 179.5; $P=0.007$ ), tumor size (OR, 16.9; 95\% CI, 1.9 152.9; $P=0.012$ ) and location (middle or upper) were significant independent predictive factors for malignant potential of gastric SETs (Table 3).
Table 3. Multivariate Analysis of Predictive Factors for Malignancy Potential of Gastric Subepithelial Tumors.

\begin{tabular}{|c|c|c|c|}
\hline Variable & Odds ratio & $\begin{array}{c}95 \% \text { confidence } \\
\text { interval }\end{array}$ & $P$ value \\
\hline \multicolumn{4}{|l|}{ Age (year) } \\
\hline$<65$ & 1 & - & - \\
\hline$\geq 65$ & 20.4 & $2.3 \sim 179.5$ & 0.007 \\
\hline \multicolumn{4}{|l|}{ Tumor size (cm) } \\
\hline$<2$ & 1 & - & - \\
\hline$\geq 2$ & 16.9 & $1.9 \sim 152.9$ & 0.012 \\
\hline \multicolumn{4}{|l|}{ Tumor location } \\
\hline Lower & 1 & - & - \\
\hline Middle & 19.4 & $2.7 \sim 137.6$ & 0.003 \\
\hline Upper & 8.6 & $1.5 \sim 48.7$ & 0.015 \\
\hline \multicolumn{4}{|l|}{ Originating layer } \\
\hline Second layer (MM) & 1 & - & - \\
\hline Third layer (SM) & 0.63 & $0.002 \sim 1.6$ & 0.098 \\
\hline Fourth layer (PM) & 2.2 & $0.4 \sim 14.1$ & 0.392 \\
\hline
\end{tabular}

$\mathrm{MM}$, muscularis mucosa; SM, submucosa; PM, muscularis propria.

\section{DISCUSSION}

In this study, we showed here that clinical factors, including patient's age, tumor location, and size were more accurate predictors of malignant potential than EUS features, like echogenicity. In addition, approximately one third of resected SETs are benign tumors, which means that these tumors are not necessarily removed.

Although EUS has been reported as a useful tool in differential diagnosis of gastrointestinal SETs and in prediction of malignant lesions, ${ }^{5,14}$ the diagnostic accuracy of EUS for SETs was relatively low and the rate of unnecessary resection for benign SETs (leiomyoma, schwannoma, etc) was approximately one-third in our data. These data were consistent with those of a previous nationwide gastric SMT report in Korea. ${ }^{15}$ To avoid unnecessary resection for benign SETs, more accurate predictive factors for malignancy of SETs are required.

A few studies have reported an association of predictive factors, such as tumor size, with malignant potential in gastric SETs. However, in these studies, not all GISTs were considered as potentially malignant or most studies were analyzed prior to introduction of the concept of GISTs. On the other hand, we analyzed our data assuming that all GISTs were potentially malignant.

In 1992, Rösch et al. ${ }^{16,17}$ compared the EUS features of 
benign tumors with those of malignant tumors in SMT of the upper GI tract, and concluded there was no single reliable criterion that would enable a differential diagnosis. However, they proposed larger, echo-inhomogeneous masses with irregular outer borders are suggestive of malignancy, whereas smaller $(<3 \mathrm{~cm})$ echo-homogeneous SETs with a smooth margin are likely to be benign.

Chak et al. ${ }^{18}$ reported that features predictive of malignant SETs included diameter $>4 \mathrm{~cm}$, irregular extraluminal border, echogenic foci, and cystic space. When the presence of at least two of the following three features were used as determinants of malignancy, sensitivity ranged from $80 \%$ to $100 \%$, depending on the endosonographer.

In a recent study, Kim et al. ${ }^{19}$ compared the EUS features of gastric GISTs with leiomyomas, and concluded that EUS features such as inhomogenicity, hyperechogenic spots, a marginal halo, and higher echogenicity, as compared with the surrounding muscle layer, may be helpful in differentiation of GISTs from leiomyomas.

In our study, the patient's gender, symptoms, echogenicity in EUS, change of size and extramural lesion did not differ between benign and malignant potential of gastric SETs.

On the other hand, most cases of gastrointestinal bleeding $(n=7)$ in gastric SETs were GISTs. Among 12 cases (2 cases were confirmed by endoscopy) of increased tumor size ( $\mathrm{n}=12$ ), seven cases were GISTs, however, five cases were benign (schwannoma, hamartomatous inverted polyp, ectopic pancreas and inflammatory myofibroblastic tumor). Extrinsic compression of three stomach lesions (one case was confirmed by endoscopy) was observed in two cases of GISTs and in one case of schwannoma. However, we were not able to obtain adequate statistical results because the sample sizes of these cases were too small.

The presumptive diagnosis on EUS imaging alone and the final pathologic diagnosis matched in $43 \%$ to $75 \%$ of cases. $^{20,21}$ In our data, the diagnostic accuracy of EUS for SETs was $58.6 \%(51 / 87)$. The third layer appeared more frequently in benign gastric SETs and the fourth layer in malignant potential. However, there were 14 benign SETs in the fourth layer (seven schwannomas, five leiomyomas, one ectopic pancreas, and one hamartomatous inverted polyp). Differentiation between leiomyomas, schwannomas, and GISTs using imaging modality only, even with EUS, is extremely difficult. ${ }^{17}$ Hyperechoic, homogenous third layer lesions are always lipomas, ${ }^{7}$ and require no further evaluation. However, hypoechoic third layer lesions can include both benign and potentially malignant lesions.

In our data, 12 cases of resections were performed in less than $2 \mathrm{~cm}$ sized tumors. Six cases of resections were performed by endoscopic methods and other 6 cases were performed by surgical methods. Most cases of resections in less than $2 \mathrm{~cm}$ sized tumors were approached because of strongly suspected malignant potential (GIST, carcinoid or increased tumor size) in EUS. However, only 3 cases were histologically confirmed as malignant potential and others were benign. All 4 cases of increased tumor size were benign.

Therefore, in order to avoid unnecessary resections, EUS guided tissue sampling should be strongly considered for hypoechoic lesions located in the third and fourth ultrasonic layer. Because it is located deeper than epithelium, we cannot take specimens from the subepithelial lesion using conventional endoscopic biopsy methods.

Many methods have been introduced for this purpose, mainly by endoscopic ultrasonography, including endoscopic ultrasound-guided fine needle aspiration (EUS-FNA), EUS-guided trucut biopsy (TCB), and EUS-guided fine needle biopsy. Significant efforts have been made to increase the diagnostic yields of submucosal lesions; however, each method has its own limitations. ${ }^{22}$

EUS-FNA is a safer and more accurate non-invasive method, compared with other methods of obtaining samples of the SET, ${ }^{23,24}$ however, EUS-FNA is not always sufficient for determination of malignancy, especially determination of malignant GISTs. ${ }^{17}$ Each diagnosis and treatment plan should be tailored to the location on the SETs. For example, EUS-guided TCB is especially useful for exploration of tumors in the cardia. ${ }^{25}$ In order to avoid unnecessary resection, more accurate tools for histologic confirmation should be developed.

EUS-guided single-incision needle-knife biopsy was recently introduced as an easy, safe, and effective technique 
for accurate diagnosis, evaluation of malignant potential, and treatment management of SETs. ${ }^{26}$ In addition, the unroofing technique was reported as a feasible option for making a diagnosis of the $\mathrm{SET}^{27}$

This study had some limitations. First, this was a retrospective study, so that there might have been a potential bias during retrospective review of endosonographic photos. Second, these results may be influenced by a selection bias since many patients with larger tumors tend to be treated with surgical resection.

In conclusion, only two-thirds of resected SETs have malignant potential. Old age ( $\geq 65$ years), as well as tumor size $(\geq 2 \mathrm{~cm})$ and location (middle or upper of stomach), rather than EUS finding alone are independent predictive factors for malignant potential of gastric SETs. Therefore, EUS guided tissue sampling should be strongly considered for hypoechoic lesions located in the third and fourth ultrasonic layer.

\section{REFERENCES}

1. Landi B, Palazzo L. The role of endosonography in submucosal tumours. Best Pract Res Clin Gastroenterol 2009;23:679-701.

2. Polkowski M, Butruk E. Submucosal lesions. Gastrointest Endosc Clin N Am 2005;15:33-54.

3. Nickl N. Endoscopic approach to gastrointestinal stromal tumors. Gastrointest Endosc Clin N Am 2005;15:455-466.

4. Polkowski M. Endoscopic ultrasound and endoscopic ultrasound-guided fine-needle biopsy for the diagnosis of malignant submucosal tumors. Endoscopy 2005;37:635-645.

5. Zhang QL, Nian WD. Endoscopic ultrasonography diagnosis in submucosal tumor of stomach. Endoscopy 1998;30 Suppl 1:A69-A71.

6. Rösch T. Endoscopic ultrasonography in upper gastrointestinal submucosal tumors: a literature review. Gastrointest Endosc Clin N Am 1995;5:609-614.

7. Chak A. EUS in submucosal tumors. Gastrointest Endosc 2002;56(4 Suppl):S43-S48.

8. Boyce GA, Sivak MV Jr, Rösch T, et al. Evaluation of submucosal upper gastrointestinal tract lesions by endoscopic ultrasound. Gastrointest Endosc 1991;37:449-454.

9. Van Dam J, Zuccaro G Jr, Sivak MV Jr. Endosonographic diagnosis of a submucosal gastric cyst. J Ultrasound Med 1992; 11:61-63.

10. Geller A, Wang KK, DiMagno EP. Diagnosis of foregut duplication cysts by endoscopic ultrasonography. Gastroenterology 1995;109:838-842.

11. Franquemont DW. Differentiation and risk assessment of gas- trointestinal stromal tumors. Am J Clin Pathol 1995;103:41-47.

12. Raut CP, DeMatteo RP. Evidence-guided surgical management of GIST: Beyond a simple case of benign and malignant. Ann Surg Oncol 2008;15:1542-1543.

13. Suzuki T, Arai M, Matsumura T, et al. Factors associated with inadequate tissue yield in EUS-FNA for gastric SMT. ISRN Gastroenterol 2011;2011:619128.

14. Takada N, Higashino M, Osugi H, Tokuhara T, Kinoshita H. Utility of endoscopic ultrasonography in assessing the indications for endoscopic surgery of submucosal esophageal tumors. Surg Endosc 1999;13:228-230.

15. The Information Committee of the Korean Gastric Cancer Association. 2005 2006 nationwide gastric submucosal tumor report in Korea. J Korean Gastric Cancer Assoc 2008;8:104109.

16. Rösch T, Lorenz R, Dancygier H, von Wickert A, Classen M. Endosonographic diagnosis of submucosal upper gastrointestinal tract tumors. Scand J Gastroenterol 1992;27:1-8.

17. Sakamoto H, Kitano M, Kudo M. Diagnosis of subepithelial tumors in the upper gastrointestinal tract by endoscopic ultrasonography. World J Radiol 2010;2:289-297.

18. Chak A, Canto MI, Rösch T, et al. Endosonographic differentiation of benign and malignant stromal cell tumors. Gastrointest Endosc 1997;45:468-473.

19. Kim GH, Park do Y, Kim S, et al. Is it possible to differentiate gastric GISTs from gastric leiomyomas by EUS? World J Gastroenterol 2009;15:3376-3381.

20. Hwang JH, Saunders MD, Rulyak SJ, Shaw S, Nietsch H, Kimmey MB. A prospective study comparing endoscopy and EUS in the evaluation of GI subepithelial masses. Gastrointest Endosc 2005;62:202-208.

21. Hoda KM, Rodriguez SA, Faigel DO. EUS-guided sampling of suspected GI stromal tumors. Gastrointest Endosc 2009;69: 1218-1223.

22. Moon JS. Endoscopic ultrasound-guided fine needle aspiration in submucosal lesion. Clin Endosc 2012;45:117-123.

23. Williams DB, Sahai AV, Aabakken L, et al. Endoscopic ultrasound guided fine needle aspiration biopsy: a large single centre experience. Gut 1999;44:720-726.

24. Wiersema MJ, Vilmann P, Giovannini M, Chang KJ, Wiersema LM. Endosonography-guided fine-needle aspiration biopsy: diagnostic accuracy and complication assessment. Gastroenterology 1997;112:1087-1095.

25. Lee JH, Choi KD, Kim MY, et al. Clinical impact of EUS-guided Trucut biopsy results on decision making for patients with gastric subepithelial tumors $\geq 2 \mathrm{~cm}$ in diameter. Gastrointest Endosc 2011;74:1010-1018.

26. Park H, Chung JW, Kim AJ, et al. A case of rectal mucosa-associated lymphoid tissue lymphoma diagnosed by endoscopic unroofing technique. Korean J Gastroenterol 2012;59:428-432.

27. de la Serna-Higuera C, Pérez-Miranda M, Díez-Redondo P, et al. EUS-guided single-incision needle-knife biopsy: description and results of a new method for tissue sampling of subepithelial GI tumors (with video). Gastrointest Endosc 2011;74:672-676. 